\title{
Effect of Binge Drinking on Glucose Metabolism in Occasional Drinkers: An Experimental Study
}

\author{
Nawé Justine Astrid Ngandeu1,2*, Armand Mbanya1,3, Eric Lontchi-Yimagou ${ }^{3,4}$, Vicky Kamwa1, \\ Jean Louis Nguewa ${ }^{5}$, Jean-Claude Katte ${ }^{1}$, Andrea Michèle Audrey Omengue ${ }^{1,6}$, \\ Simeon-Pierre Choukem ${ }^{7,8}$, Mesmin Dehayem ${ }^{1,6}$, Jean-Claude Mbanya ${ }^{1,4,6}$, Eugene Sobngwi ${ }^{1,4,6}$ \\ ${ }^{1}$ Yaounde Central Hospital, National Obesity Center, Yaoundé, Cameroon \\ ${ }^{2}$ Cocody's CHU, Abidjan, Ivory Coast \\ ${ }^{3}$ Diabetes Research and Training Center and Division of Endocrinology, Department of Medicine, Albert Einstein College of \\ Medicine, New York, NY, USA \\ ${ }^{4}$ Laboratories of Molecular Medicine and Metabolism, Biotechnology Center, University of Yaoundé, \\ Yaoundé, Cameroon \\ ${ }^{5}$ Inserm UMRS 1138, Cordeliers Research Centre, University of Paris, Paris, France \\ ${ }^{6}$ Department of Internal Medicine, Faculty of Medicine and Biomedical Sciences, University of Yaoundé, \\ Yaoundé, Cameroon \\ ${ }^{7}$ Departments of Internal Medicine and Pediatrics, Faculty of Health Sciences, University of Buea, Buea, Cameroon \\ ${ }^{8}$ Health and Human Development (2HD) Research Group, Douala, Cameroon \\ Email: *astridnawe@gmail.com
}

How to cite this paper: Ngandeu, N.J.A., Mbanya, A., Lontchi-Yimagou, E., Kamwa, V., Nguewa, J.L., Katte, J.-C., Omengue, A.M.A., Choukem, S.-P., Dehayem, M., Mbanya, J.-C. and Sobngwi, E. (2018) Effect of Binge Drinking on Glucose Metabolism in Occasional Drinkers: An Experimental Study. Open Journal of Endocrine and Metabolic Diseases, 8, 49-58. https://doi.org/10.4236/ojemd.2018.81006

Received: December 23, 2017

Accepted: January 19, 2018

Published: January 22, 2018

Copyright $\odot 2018$ by authors and Scientific Research Publishing Inc. This work is licensed under the Creative Commons Attribution International License (CC BY 4.0).

http://creativecommons.org/licenses/by/4.0/

\begin{abstract}
Binge drinking is a major public health problem that affects all age groups. Its relation to the risk of impaired glucose metabolism and diabetes is unclear due to controversial findings in animal models and lack of studies in humans. We performed an experimental study on 10 adult volunteers $(7 \mathrm{M} / 3 \mathrm{~F})$ under the age of 40 who were occasional binge drinkers. In all participants, we performed a baseline two-hour euglycemic hyperinsulinemic clamp at $80 \mathrm{mU} \cdot \mathrm{m}^{-2} \cdot \mathrm{min}^{-1}$ at baseline for comparison with an age and sex matched control population of non-drinkers. On a second occasion, before and after ingestion of $78 \mathrm{~g}$ of alcohol (beer) in $2 \mathrm{hrs}$ we also measured insulin sensitivity using a 15-minute short insulin tolerance test in drinkers. Blood glucose was also measured every 15 mins over 2 hours during alcohol ingestion. Volunteers were aged $27.6 \pm 5.7$ years, with a BMI of $23.1 \pm 2.8 \mathrm{~kg} / \mathrm{m}^{2}$, and ALAT of $24.7 \pm 3.0 \mathrm{UI} / \mathrm{L}$. Insulin sensitivity evaluated by the clamp technique was higher in occasional drinkers $\left(\mathrm{M}=12.7 \pm 3.4 \mathrm{mg} \cdot \mathrm{kg}^{-1} \cdot \mathrm{min}^{-1}\right.$ vs. $8.0 \pm 2.3 \mathrm{mg} \cdot \mathrm{kg}^{-1} \cdot \mathrm{min}^{-1}$ in non-drinkers, $\mathrm{p}=$ 0.011). Acute alcohol ingestion was associated with a non-significant trends towards improved glucose disappearance during short insulin tolerance test (KITT $2.53 \% \pm 0.22 \% / \mathrm{min}$ before vs. $3.11 \% \pm 1.15 \% / \mathrm{min}$ after; $\mathrm{p}=0.122$ ). Beer consumption induced a significant increase in capillary glycaemia of $78 \%$
\end{abstract}


$(\mathrm{p}=0.001)$. Bingeing was associated with reduced insulin secretion (Homa- $\beta$ $113.5 \pm 22.7$ vs. $155.4 \pm 57.6 ; \mathrm{p}=0.047)$. Binge drinking may induce an increase in insulin sensitivity but acutely decrease insulin secretion.

\section{Keywords}

Glucose Metabolism, Binge Drinking, Insulin Sensitivity, Insulin Secretion

\section{Introduction}

Alcohol is the third highest risk factor for morbidity and mortality after hypertension and smoking. It is a known etiological factor for over 200 diseases [1]. The most frequent drinking pattern is binge drinking, but epidemiological studies have mostly focused on chronic alcohol consumption. Binge drinking is defined as the consumption of 4 or more drinks containing alcohol on the same occasion for a woman; and five or more drinks on one occasion in a man over a period of about 2 hours [2]. Binge drinking is a public health problem and is linked to an increased incidence in type 2 diabetes and metabolic syndrome, however, the mechanism by which binge drinking affects glucose metabolism remains unclear [3]. This increased incidence with binge drinking has been attributed to increased insulin resistance. Alcohol may directly induce insulin resistance or may be linked to increased caloric intake as a result of alterations in central reward pathways [4]. Chronic alcohol consumption is known to affect insulin secretion but little is known about binge drinking. Most evidence to date is derived from animal studies, limited data exist in humans associating binge drinking to impaired glucose metabolism. We therefore evaluated the acute effects of binge drinking on glucose metabolism, specifically glycaemic profile during binge drinking, insulin sensitivity and insulin secretion.

\section{Methods}

\section{1) Study Population}

We carried out an experimental study at the Clinical Investigation Unit of the Department of Endocrinology and Metabolic disease of Yaoundé Central Hospital, Yaoundé (Cameroon). We enrolled by advertisement 10 young adults (7 males and 3 females) reporting a habit of binge drinking at least once a week for the past year with a reported minimum of 4 glasses for females or 5 glasses for males in a session (average alcohol consumption was $72.9 \pm 7.8 \mathrm{~g} /$ occasion). Desire to stop alcohol consumption, obesity, coexisting disease, the use of any medication that could have an effect insulin sensitivity or secretion, variation in weight $\geq 10 \%$ during the 3 months prior to the study, acute alcohol consumption less than 3days prior to study, elevated fasting capillary glycaemia, recent infection less than ten days prior to inclusion, high hepatic transaminase ALAT $(3 \times$ normal) and creatinine clearance $\leq 60 \mathrm{ml} / \mathrm{min} / 1.73 \mathrm{~m}^{2}$ were exclusion criteria. 
The 10 test volunteers were compared to age and sex matched 10 control volunteers reporting no alcohol consumption. The sample size was calculated from an expected change of insulin sensitivity of at least $20 \%$ from baseline in drinker. Choosing $\alpha$ at $5 \%, \beta$ at $20 \%$, and a statistical power of $80 \%$, the calculated sample size is 10 subjects. The study protocol was approved by the Institutional Research Ethical Committee of the Faculty of Medicine and Biomedical Sciences Yaoundé and by the institutional review board of the Yaoundé Central Hospital.

\section{2) Procedure}

After collecting lifestyle and background data and performing clinical examination, we measured baseline insulin sensitivity by an $80 \mathrm{~m} \cdot \mathrm{Um}^{-2} \cdot \mathrm{min}^{-1}$ euglycemic-hyperinsulinemic clamp. Pre- and post-intervention insulin sensitivity was measured using the short insulin tolerance test.

\section{a) Euglycemic-Hyperinsulinemic Clamp}

After overnight fast of at least 8 hours, rapid insulin (Actrapid ${ }^{\circledR}$ HM Novo Nordisk A/S, DK-2880 Bagsvaerd, Denmark) in a syringe pump (ALARIS ${ }^{\circledR}$ MEDICAL SYSTEMS UK Ltd., Basingstoke, RG22 4BS, UK) and 10\% dextrose solution were infused via the right anterior cubital vein using an infusion pump (IVAC Corporation-Model 598, San Diego, California). Blood sampling was done through the left anterior cubital vein. A priming infusion of insulin was given over the first 10 minutes followed by a constant supraphysiological infusion rate of $80 \mathrm{mU} \cdot \mathrm{m}^{-2} \cdot \mathrm{min}^{-1}$ until the 120 th minute. Dextrose infusion rate was adjusted every 5 minutes with the aim of maintaining capillary blood sugar levels at $5.5 \pm$ $0.5 \mathrm{mmol} / \mathrm{L}$ (My Life ${ }^{\circledR}$ Pura $^{\circledR}$ Ypsomed Ltd., CH-3401 Burgdorf/Switzerland). Insulin sensitivity was calculated at the steady state by the $\mathrm{M}$-value $\left(\mathrm{mg} \cdot \mathrm{kg}^{-1} \cdot \mathrm{min}^{-1}\right)$ which represents glucose disposal rate during insulin infusion and was adjusted to lean body mass [5].

\section{b) Short Insulin Tolerance Test and Binge Drinking Test}

Following an overnight fast, an intravenous injection of $0.15 \mathrm{UI} / \mathrm{kg}$ of insulin (Actrapid ${ }^{\circledR}$ HM Novo Nordisk A/S 2880 Bagsvaerd, Denmark), diluted in 2cc of isotonic saline was done. Capillary glycemia was measured before and at the $3 \mathrm{rd}$, 6th, 9th, 12th, and 15th minute after injection. Short insulin tolerance test (SITT)-derived insulin sensitivity was calculated by the slope of the linear drop in blood glucose (KITT) by dividing 0.693 by the half-life of the drop in blood sugar. One hour after the first SITT, the volunteers ingested $78 \mathrm{~g}$ of alcohol over 2 hours. Capillary blood glucose was measured every 15 minutes during alcohol consumption. At the end of the 2-hour period, the insulin tolerance test was repeated.

\section{3) Analytical Methods}

Glucose was analyzed by the glucose oxidase method. Lipid profile was determined by enzymatic colorimetric methods. Fat mass and BMI was evaluated using electrical bio-impedance. C-peptide levels were measured by enzyme linked immunosorbent assay (ELISA) with the IBL C-peptide Enzyme Immunoassay Kit from Mercodia ${ }^{\circledR}$ (Mercodia AB, Sylveniusgatan 8A, SE-754 50, Uppsala, Sweden) which had been previously validated in our laboratory functional sensi- 
tivity of $0.32 \mu \mathrm{g} / \mathrm{L}$. The inter- and intra-assay \% CV were $2.9 \%-9.9 \%$, and $5.2 \%$ $9.4 \%$, respectively [6]. Homa- $\beta$ was calculated using the following formula: 0.27 $\times$ fasting C-peptide/(fasting glycemia- $3.5 \mathrm{mmol})+50$ to estimate insulin secretion.

Results were expressed as mean \pm SD. Means were compared between groups with the Student's test and Fischer's exact test. Graphs were made in graph pad prism software version 5. KITTs and $M$ values were calculated using predesigned excel sheets from our previous study [6]. A p value $<0.05$ was considered statistically significant for all analyses.

\section{Results}

\section{1) General Characteristics of the Study Population}

We had 15 volunteers at the start, having responded to our invitation, but only 10 who presented themselves. We had a response rate of about $67 \%$. They consisted of 7 men and 3 women. Their mean age was $28 \pm 6$ years. Our study population consisted of two groups; binge drinkers and non-drinkers of alcohol. Table 1 shows the baseline characteristics of our study population. Binge drinkers had higher diastolic blood pressure than non-drinkers $(\mathrm{p}=0.014)$.

\section{2) Baseline Insulin Sensitivity and Insulin Secretion}

During the euglycemic hyperinsulinemic clamp, glucose uptake ( $\mathrm{M}$ value) was $12.7 \pm 3 \mathrm{mg} \cdot \mathrm{kg}^{-1} \cdot \mathrm{min}^{-1}$ in drinkers vs. $8.1 \pm 2.3 \mathrm{mg} \cdot \mathrm{kg}^{-1} \cdot \mathrm{min}^{-1}$ in non-drinkers ( $\mathrm{p}$ $=0.011)$. Similar trends remained after adjustment for body lean mass $(\mathrm{M}=15.0$ \pm 3.3 vs. $10 \pm 2.0 \mathrm{mg} \cdot \mathrm{kg}^{-1} \cdot \mathrm{min}^{-1} ; \mathrm{p}=0.007$ ) as shown in Table 1 . There was no difference in C-peptide levels which is the marker for insulin secretion in both groups but Homa- $\beta$ was lower in drinkers ( $p=0.047)$. The relation between insulin sensitivity and insulin secretion is showed in Figure 1.

\section{3) Metabolic Effect of Ingestion $78 \mathrm{~g}$ of Alcohol over $2 \mathrm{hrs}$}

Alcohol (beer) was ingested for two hours during which blood sugar levels rose significantly (Figure 2 and Table 2 ). The insulin sensitivity of the volunteers increased by about $23 \%$ after ingesting alcohol (KITT $=2.53 \pm 0.22 \% / \mathrm{min}$ before vs. $3.11 \pm 1.15 \% / \mathrm{min}$ after; $\mathrm{p}=0.122$ ).

Table 1. Baseline characteristics of participants.

\begin{tabular}{cccc}
\hline & Subjects & Controls & $\mathrm{p}$ \\
\hline Number & $10(\mathrm{~F}=3 ; \mathrm{M}=7)$ & $08(\mathrm{~F}=3 ; \mathrm{M}=5)$ & - \\
Ages (années) & $28 \pm 6$ & $28 \pm 5$ & 0.78 \\
TT en cm & $78.2 \pm 7.6$ & $82.0 \pm 12.1$ & 0.469 \\
TH en cm & $85.6 \pm 7.9$ & $94.0 \pm 11.0$ & 0.166 \\
Rapport TT/TH & $0.9 \pm 0.3$ & $0.9 \pm 0.7$ & 0.123 \\
IMC en Kg/m ${ }^{2}$ & $23.1 \pm 2.9$ & $24.5 \pm 4.4$ & 0.459 \\
masse grasse en \% & $15.3 \pm 5.0$ & $19.3 \pm 10.3$ & 0.216 \\
PAS en mmHg & $122 \pm 10$ & $115 \pm 7$ & 0.154 \\
PAD en mmHg & $78 \pm 8$ & $68 \pm 6$ & 0.014 \\
PAM en mmHg & $93 \pm 8$ & $84 \pm 5$ & 0.027 \\
\hline
\end{tabular}




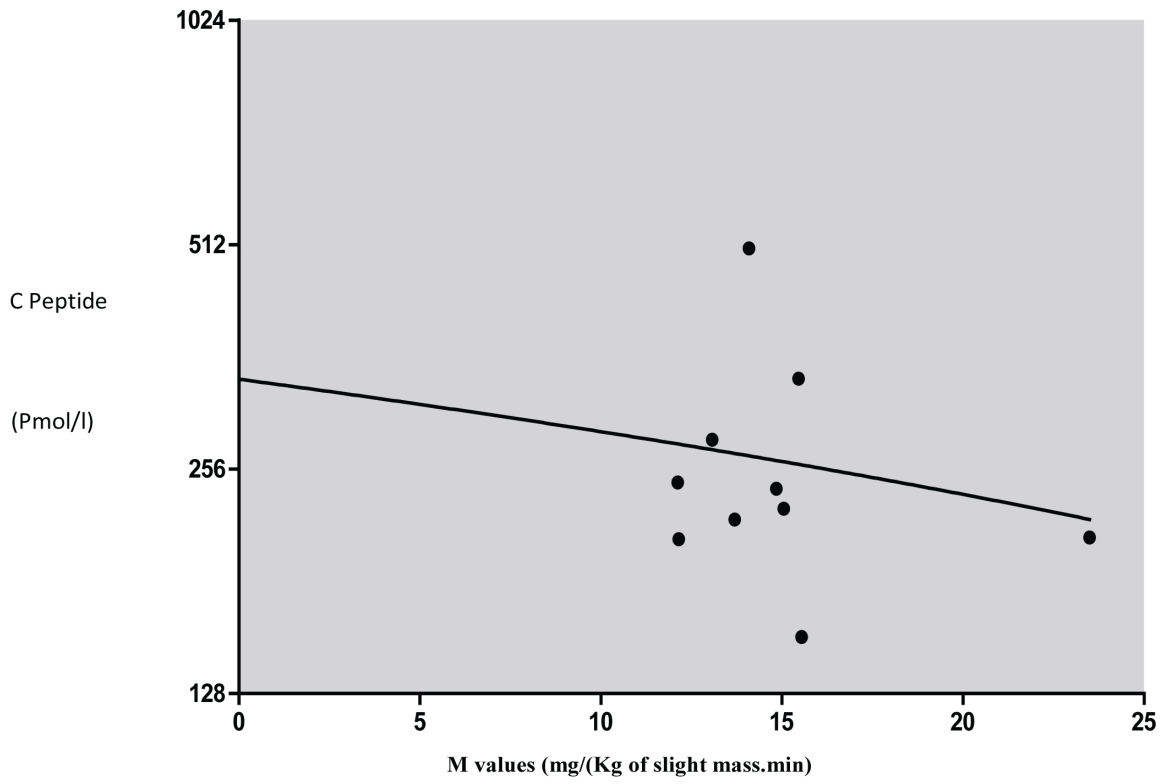

Figure 1. Relation between insulin sensitivity and insulin secretion.

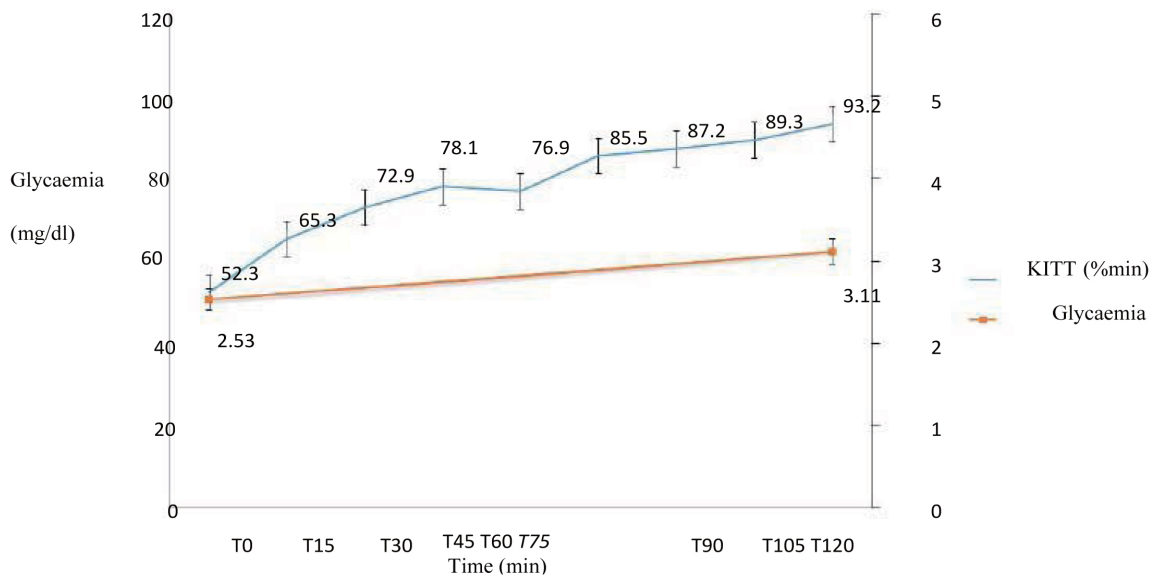

Figure 2. Changes in blood glucose profile in $\mathrm{mg} / \mathrm{dl}$ during the ingestion of alcohol every 15 minutes over two hours and in insulin sensitivity (KITT) before and after ingestion of $78 \mathrm{~g}$ of alcohol.

Table 2. Insuline sensitivity before and after taking alcohol.

\begin{tabular}{ccccc}
\hline Subjects & KITT before & KITT after & Difference & $\mathrm{p}$ for glycemia before $/$ after \\
\hline 1 & $2.741 \% / \mathrm{min}$ & $3.14 \% / \mathrm{min}$ & $0.399 \% / \mathrm{min}$ & 0 \\
2 & $2.316 \% / \mathrm{min}$ & $2.949 \% / \mathrm{min}$ & $0.633 \% / \mathrm{min}$ & 0.04 \\
3 & $2.432 \% / \mathrm{min}$ & $5.001 \% / \mathrm{min}$ & $2.569 \% / \mathrm{min}$ & 0 \\
4 & $2.462 \% / \mathrm{min}$ & $3.3 \% / \mathrm{min}$ & $0.838 \% / \mathrm{min}$ & 0.001 \\
5 & $2.401 \% / \mathrm{min}$ & $2.069 \% / \mathrm{min}$ & $-0.332 \% / \mathrm{min}$ & 0.27 \\
6 & $2.527 \% / \mathrm{min}$ & $1.852 \% / \mathrm{min}$ & $-0.675 \% / \mathrm{min}$ & 0.195 \\
7 & $2.862 \% / \mathrm{min}$ & $3.09 \% / \mathrm{min}$ & $0.228 \% / \mathrm{min}$ & 0.174 \\
8 & $2.343 \% / \mathrm{min}$ & $2.025 \% / \mathrm{min}$ & $-0.318 \% / \mathrm{min}$ & 0.001 \\
9 & $2.372 \% / \mathrm{min}$ & $2.56 \% / \mathrm{min}$ & $0.188 \% / \mathrm{min}$ & 0 \\
10 & $2.905 \% / \mathrm{min}$ & $5.133 \% / \mathrm{min}$ & $2.228 \% / \mathrm{min}$ & 0 \\
Mean & $2.54 \pm 0.22 \% / \mathrm{min}$ & $3.11 \pm 1.15 \% / \mathrm{min}$ & - & 0.122 \\
\hline
\end{tabular}




\section{Discussion}

The aim of our study was to evaluate the effects of acute alcohol consumption on glucose metabolism in the occasional binge drinker. Our results demonstrate that in the study population, binge drinking is associated with an acute increase in insulin sensitivity and a $36.7 \%$ reduction in insulin secretion. The consumption of $78 \mathrm{~g}$ of alcohol in the form of beer acutely induces a progressive increase in glycemia of about $78 \%$, along with an improvement in the insulin sensitivity of $22.9 \%$. Binge drinking is the most common way of alcohol consumption in the world and yet is little studied in terms of glucose metabolism. The majority of work focuses on chronic alcohol consumption. In order to assess insulin sensitivity at base line, we performed the euglycemic hyperinsulinemic clamp technique which is the gold standard [7]. Measuring variations of insulin sensitivity requires an accurate and reproducible technique; it was done by the short test of tolerance to insulin, which has the advantage of a good correlation with the clamp [8]. The beer brand Guinness ${ }^{\circledR}$ as type of alcohol was chosen after a survey amongst volunteers, and allows for the reproducibility of the test, in a wide range of countries Insulin secretion was measured based on Homa- $\beta$ using fasting C-peptide levels.

Epidemiological studies on alcohol consumption with regard to type 2 diabetes are controversial. Findings have varied, with non-alcohol consumers presenting with a higher relative risk vs. alcohol consumers [9]. Nakanishi in 2003 in a cohort studied for 7 years, based on the principle of a U-shaped relationship between alcohol and type 2 diabetes implying that moderate alcohol consumption reduces the risk of glucose intolerance and diabetes type 2 in healthy Japanese [10]. In patients previously intolerant to glucose, alcohol can worsen this condition [11]. The work of Cullman and collaborators in 2012 [12] show that binge drinking by a high consumption of beer increases the risk of pre-diabetes in both sexes; and consumption of large amounts of wine and spirits reduces the risk of diabetes in women.

Glucose intolerance is caused by a variable association between insulin sensitivity and insulin secretion. In order to understand the relationship between alcohol and the occurrence of type 2 diabetes, a detailed assessment of these two parameters must be carried out. With respect to insulin sensitivity, we found that $\mathrm{M}$-value adjusted for lean mass in occasional binge drinkers was higher than in controls revealing higher insulin sensitivity. Similarly, there was an increase in the KITT after bingeing in our study. Facchini et al. in 1994, had similar results in individuals who usually moderate alcohol consumption ( $30 \mathrm{~g})$ evaluating their insulin sensitivity by oral glucose tolerance test. His findings indicated that moderate consumers of alcohol have insulin sensitivity better than that of controls [13]. The improved insulin sensitivity in binge drinkers may be explained in several ways. The waist circumference and percentage of fat mass though not significant of subjects in our study is lower which may indicate less abdominal fat than in controls hence higher insulin sensitivity. These results are in agreement with those of Schlieng- 
er et al. in 2008 show that the favorable relationship between alcohol consumption and the insulin sensitivity could be mediated in part by the impact of alcohol on abdominal obesity [14] [15]. Furthermore, it is understood that reducing the early peak of insulin secretion leads to loss of inhibition of hepatic glucose production in response to a meal and an elevation of postprandial glucose [16]. In animal models, binge drinking induces an increase in the suppression of hepatic glucose production, which could explain the improvement of insulin sensitivity observed in the acute drinkers. Animal studies, stipulate that the main mechanism of binge drinking on glucose metabolism is by inducing whole-body insulin resistance by impairing hypothalamic insulin action but not liver insulin signaling [17]. In addition, bingeing is known to induce oxidative stress as a result of alcohol metabolism [18] and increases expression and processing of cytokines and chemokines, recruiting and accumulation of inflammatory cells and macrophage oxidative capacity particularly in adipose tissue [19]. This may account for adipose tissue resistance to alcohol. Globally, the acute effects of binge drinking on insulin sensitivity remain controversial.

Though our findings suggest an acute improvement in insulin sensitivity, it is necessary to follow people who binge over time to determine of the findings in animal models develop at a later time post-bingeing. Insulin secretion in the alcohol consumer, irrespective of the mode of consumption has been scantily studied. We found a reduced insulin secretion in chronic binge drinkers. Alcohol has known deleterious effects on the pancreas which may explain this decrease in insulin secretion. Also alcohol induces systemic elevation of cathecholamines leading to activation of lipolytic enzymes [20] and decreasing insulin secretion. Insulin secretion shares an important relationship with insulin sensitivity. Indeed, in non-diabetic subjects, insulin resistance is compensated by an increase in insulin secretion and vice versa. Our results show that the volunteers who had a very good sensitivity to insulin, paradoxically have reduced insulin secretion; which confirms the inverse relationship presented by Ahren et al. [21]. Though we did not measure hepatic glucose production, in animal models, a hyperinsulinemic euglycemic clamp with tracer shows that in binge model rats, the suppression of hepatic glucose production is statistically higher than in control rats (96\% vs. $74 \%$ ). We can conclude that binge drinking is linked to prolonged impairment of glucose metabolism [11]. It is known that regular alcohol consumption is harmful to the liver. Transaminases may not be increased when the liver is already suffering. Among the volunteers, $100 \%$ had normal transaminases, and $50 \%$ of them increased GGT values. We found no correlation between the amount of alcohol and the occasional normal values; although, there is a negative correlation between GGT and value M. This would mean that the more gamma GT values are high, the more insulin sensitivity is low, and therefore the damage induced by alcohol to the liver has a deleterious effect on insulin sensitivity. Regarding the effects of alcohol on blood sugar, you should know that it is affected by the energy value of the alcohol consumed and its total carbohydrates content per volume consumed. With this property, by its composition (Glycemic 
Index $=110$ ) as cited in the literature it is not surprising that we found an increase in blood sugar of around $78 \%$ in two hours ingestion of beer.

\section{Summary}

The metabolic effects of binge drinking seem to be favorable when considering the sensitivity to insulin. It is unlikely that this is the result of a reduced risk of diabetes given the observed decrease in insulin secretion. Though, our results suggest this, there are multiple health risks and negative effects of alcohol consumption irrespective of the mode of consumption hence it should not be used in an abusive manner.

\section{Competing Interest}

The authors have no conflict of interest to declare.

\section{Authors' Contribution}

ANN: researched, analyzed and interpreted data, drafted the manuscript. AM: researched data, drafted, reviewed and edited the manuscript. VK: researched data. OTD: analyzed data. ELY: researched data. JLN: Researched data. JCM and ES: Designed the study, interpreted data, reviewed and edited the manuscript. All authors read and approved the final manuscript.

\section{Acknowledgements}

We show our sincere gratitude to the patients who participated in this study and to the nursing and laboratory staff at the National Obesity Centre, Yaoundé, Cameroon.

\section{References}

[1] O’Keefe, J.H., Bhatti, S.K., Bajwa, A., DiNicolantonio, J.J. and Lavie, C.J. (2014) Alcohol and Cardiovascular Health: The Dose Makes the Poison...or the Remedy. Mayo Clinic Proceedings, 89, 382-393. https://doi.org/10.1016/j.mayocp.2013.11.005

[2] Blazer, D.G. and Wu, L.T. (2009) The Epidemiology of At-Risk and Binge Drinking among Middle-Aged and Elderly Community Adults: National Survey on Drug Use and Health. The American Journal of Psychiatry, 166, 1162-1169. https://doi.org/10.1176/appi.ajp.2009.09010016

[3] Naimi, T.S., Brewer, R.D., Mokdad, A., Denny, C., Serdula, M.K. and Marks, J.S. (2003) BInge Drinking among US Adults. JAMA, 289, 70-75. https://doi.org/10.1001/jama.289.1.70

[4] Thiele, T.E. (2013) Insulin Resistance from Binge Drinking: It's All in Your Head. Science Translational Medicine, 5, $170 \mathrm{fs} 3$. https://doi.org/10.1126/scitranslmed.3005300

[5] Volkow, N.D., Wang, G.J. and Baler, R.D. (2011) Reward, Dopamine and the Control of Food Intake: Implications for Obesity. Trends in Cognitive Sciences, 15, 37-46. https://doi.org/10.1016/j.tics.2010.11.001

[6] Mbanya, A., Ngandeu, A., Kamwa, V., Donfack, O.T., Lontchi, É., Leke, R., Mbanya, 
J.-C. and Sobngwi, E. (2016) Metabolic Features Associated with Positivity to ZnT8 Autoantibody in Sub-Saharan African Young-Onset Diabetes Patients. Diabetes \& Metabolism, 42, 204-206. https://doi.org/10.1016/j.diabet.2015.12.002

[7] De Fronzo, R.A., Tobin, J.D. and Andres, R. (1979) Glucose Clamp Technique: A Method for Quantifying Insulin Secretion and Resistance. The American Journal of Physiology, 237, E214-E223.

[8] Gelding, S.V., Robinson, S., Lowe, S., Niththyananthan, R. and Johnston, D.G. (1994) Validation of the Low Dose Short Insulin Tolerance Test for Evaluation of Insulin Sensitivity. Clinical Endocrinology, 40, 611-615. https://doi.org/10.1111/j.1365-2265.1994.tb03012.x

[9] Wei, M., Gibbons, L.W., Mitchell, T.L., Kampert, J.B. and Blair, S.N. (2000) Alcohol Intake and Incidence of Type 2 Diabetes in Men. Diabetes Care, 23, 18-22. https://doi.org/10.2337/diacare.23.1.18

[10] Nakanishi, N., Suzuki, K. and Tatara, K. (2003) Alcohol Consumption and Risk for Development of Impaired Fasting Glucose or Type 2 Diabetes in Middle-Aged Japanese Men. Diabetes Care, 26, 48-54. https://doi.org/10.2337/diacare.26.1.48

[11] Lindtner, C., Scherer, T., Zielinski, E., Filatova, N., Fasshauer, M., Tonks, N.K., et al. (2013) Binge Drinking Induces Whole-Body Insulin Resistance by Impairing Hypothalamic Insulin Action. Science Translational Medicine, 5, 170ra14. https://doi.org/10.1126/scitranslmed.3005123

[12] Cullmann, M., Hilding, A. and Ostenson, C.G. (2012) Alcohol Consumption and Risk of Pre-Diabetes and Type 2 Diabetes Development in a Swedish Population. Diabetic Medicine: A Journal of the British Diabetic Association, 29, 441-452. https://doi.org/10.1111/j.1464-5491.2011.03450.x

[13] Facchini, F., Chen, Y.D. and Reaven, G.M. (1994) Light-to-Moderate Alcohol Intake Is Associated with Enhanced Insulin Sensitivity. Diabetes Care, 17, 115-119. https://doi.org/10.2337/diacare.17.2.115

[14] Schlienger, J.L., Pradignac, A. and Vinzio, S. (2008) Alcool, métabolisme glucique et diabète. Sang Thrombose Vaisseaux, 20, 13-18.

[15] Leggio, L., Malandrino, N., Ferrulli, A., Cardone, S., Miceli, A., Gasbarrini, G., et al. (2009) Is Cortisol Involved in the Alcohol-Related Fat Mass Impairment? A Longitudinal Clinical Study. Alcohol and Alcoholism, 44, 211-215. https://doi.org/10.1093/alcalc/agn116

[16] Caumo, A. and Luzi, L. (2004) First-Phase Insulin Secretion: Does It Exist in Real Life? Considerations on Shape and Function. American Journal of Physiology, 287, E371-E385.

[17] Garcia-Ruiz, C. and Fernandez-Checa, J.C. (2013) To Binge or Not to Binge: Binge Drinking Disrupts Glucose Homeostasis by Impairing Hypothalamic But Not Liver Insulin Signaling. Hepatology, 57, 2535-2538. https://doi.org/10.1002/hep.26423

[18] Tang, H., Sebastian, B.M., Axhemi, A., Chen, X., Hillian, A.D., Jacobsen, D.W., et al. (2012) Ethanol-Induced Oxidative Stress via the CYP2E1 Pathway Disrupts Adiponectin Secretion from Adipocytes. Alcoholism, Clinical and Experimental Research, 36, 214-222. https://doi.org/10.1111/j.1530-0277.2011.01607.x

[19] Qin, Y., Hamilton, J.L., Bird, M.D., Chen, M.M., Ramirez, L., Zahs, A., et al. (2014) Adipose Inflammation and Macrophage Infiltration after Binge Ethanol and Burn Injury. Alcoholism, Clinical and Experimental Research, 38, 204-213. https://doi.org/10.1111/acer.12210

[20] Zhao, C., Liu, Y., Xiao, J., Liu, L., Chen, S., Mohammadi, M., et al. (2015) FGF21 Mediates Alcohol-Induced Adipose Tissue Lipolysis by Activation of Systemic Re- 
lease of Catecholamine in Mice. Journal of Lipid Research, 56, 1481-1491.

https://doi.org/10.1194/jlr.M058610

[21] Ahren, B. and Pacini, G. (2004) Importance of Quantifying Insulin Secretion in Relation to Insulin Sensitivity to Accurately Assess Beta Cell Function in Clinical Studies. European Journal of Endocrinology/ European Federation of Endocrine Societies, 150, 97-104. https://doi.org/10.1530/eje.0.1500097 